\title{
Peningkatan Partisipasi Masyarakat untuk Percepatan Capaian SDG's Sektor Air Bersih dan Sanitasi
}

\author{
Bismi Annisa' ${ }^{1}$, Sri Hartati Dewi ${ }^{2}$, Harmiyati ${ }^{3}$, Vauzhea Sherlina ${ }^{4}$, Gryanda Wahyu Sugeng5 \\ 1,2,3,4,5 Program Studi Teknik Sipil, Fakultas Teknik, Univeritas Islam Riau \\ *e-mail: bismi.annisa@eng.uir.ac.id ${ }_{2}{ }_{2}$ vauzheasherli@student.uir.ac.id ${ }^{4}$,wahyugryanda11@gmail.com ${ }^{5}$
}

\begin{abstract}
The SDGs or Sustainable Development Goals are the 2030 Global Development Agenda which has become a commitment from all countries in the world, including Indonesia. Goal 6 Clean water and sanitation aims to ensure the need for clean water is adequate for all levels of society. Achieving these goals is highly dependent on community participation to help accelerate the SDG's program in the clean water and sanitation sector. The need for clean water can be met by utilizing the existing clean water supply while taking into account the impact on the environment. Rainwater has the potential to become a clean water resource by utilizing a simple rainwater harvesting system consisting of gutters, piping systems, and water tanks. By utilizing rainwater resources, it can help reduce the use of groundwater due to overexploitation of groundwater. Service activities are carried out online and offline together with partners SMPN 06 Pekanbaru by build Rain Water Harvesting (RWH) construction; so that later the RWH building can become a pilot activity/ best practice for other schools and the surrounding community.
\end{abstract}

Keywords: Clean Water, Rain Water Harvesting, Sanitation, SDG'S

\begin{abstract}
Abstrak
SDGs atau Tujuan Pembangunan Berkelanjutan merupakan Agenda Pembangunan Global Tahun 2030 yang telah menjadi komitmen dari semua Negara di dunia termasuk Indonesia. Tujuan ke-6 Air bersih dan sanitasi bertujuan untuk memastikan kebutuhan air bersih dan sanitasi layak bagi seluruh lapisan masyarakat. Pencapaian tujuan sangat bergantung kepada partisipasi masyarakat untuk turut mendorong perecepatan program SDG's sektor air bersih dan sanitasi. Kebutuhan terhadap air bersih dan sanitasi dapat terpenuhi dengan memanfaatkan pasokan air bersih yang ada dengan tetap memperhatikan dampak pada lingkungan. air hujan sangat berpotensi menjadi sumberdaya air bersih dengan memanfaatkan sistem Pemanenan Air Hujan (Rain Water Harvesting/RWH) sederhana yang terdiri dari talang, sistem perpipaan, dan tangki air. Dengan memanfaatkan sumberdaya air hujan dapat membantu mengurangi penggunaan air tanah karena ekploitasi berlebihan. Kegiatan pengabdian dilakukan secara daring dan luring bersama dengan mitra SMPN 06 Pekanbaru, dengan membangun konstruksi Pemanenan Air Hujan (PAH) dapat menjadi kegiatan percontohan bagi sekolah lain dan masyarakat sekitar.
\end{abstract}

Kata kunci: Air Bersih, Pemanenan Air Hujan, Sanitasi, SDG's

\section{PENDAHULUAN}

Air bersih dan sanitasi layak merpakan tujuan ke-6 dari program SDG's (Sustainable Developent Goals) dengan tujuan memastikan masyarakat mencapai akses universal air bersih dan sanitasi pada tahun 2030. Air atau yang disebut H2O adalah senyawa kimia yang merupakan sumber kehidupan manusia dan makhluk hidup lainnya. Bahkan dalam tubuh kita sendiri terdiri dari 55\% -78\% air (Yermadona et al., 2019).

Untuk wilayah Riau, telah tercapai target ketercapaian air bersih dan sanitasi layak pada tahun 2015 sebesar 74,24 \% untuk air bersih dan 51,3\% untuk sanitasi dengan target ketercapaian pada tahun 2030 sebesar 95,49 \% untuk air bersih dan 89,13\% untuk sanitasi (Alisjahbana,2018). Perlu dilakukan peningkatan pengelolaan air minum skala kawasan dengan menyediakan sumber air baku baru beserta sarana prasarana pengolahan, penampungan dan jaringan distribusi perpipaannya (Putri, 2018). Pemanen Air Hujan (PAH) merupakan teknologi sederhana yang dapat dibangun oleh masyarakat untuk turut berpartisipasi dalam pencapaian program SDG's sektor air bersih dan snitasi. 
Pemanenan air hujan merupakan serangkaian kegiatan mengumpulkan, menggunakan dan/atau meresapkan air hujan kedalam tanah. Air hujan merupakan salah satu sumber air yang dapat diakses secara langsung yang dapat digunakan untuk berbagai keperluan, termasuk menambah sumber pasokan air lainnya di daerah perkotaan (Rofil \& Maryono. 2017). Air hujan memiliki nilai kesadahan rendah (0) sehingga tidak membutuhkan proses pengolahan yang canggih (Quaresvita, 2016). Pada kegiatan ini, air hujan yang digunakan merupakan air hujan yang berasal dari atap bangunan sehingga air yang sudah tertampung dapat langsung dialirkan ke tangki yang terletak di permukaan tanah dengan menggunakan sistem pipa yang memanfaatkan sistem gravitasi bumi. Pompa tidak diperlukan dalam pengoperasian teknologi PAH sehingga dapat menghemat penggunaan energi listrik.

PAH merupakan teknologi yang mudah dan fleksibel dan dapat dibangun sesuai dengan kebutuhan. Pembangunan, operasional dan perawatan tidak membutuhkan tenaga kerja dengan keahlian tertentu sehingga implementasi dapat dengan mudah dilakukan tanpa memerlukan tenaga ahli. Terkait desain dan cara pembangunan PAH akan disosialisasikan kepada mitra dengan rutin melakukan pertemuan virtual menggunakan zoom meeting, penyerahan buku pedoman lengkap mengenai PAH (Pemanenan Air Hujan). Sedangkan pelaksanaan pembangunan $\mathrm{PAH}$ dirancang menggunakan standar protokol kesehatan Covid-19 yang dikoordinasikan dan dipantau secara intensif antara tim pelaksana, pihak sekolah dan tukang.

Mitra sasaran adalah mitra non profit, yakni SMPN 06 Pekanbaru terletak di Jl. Rumbai Km 2,5, Lembah Damai, Kecamatan Rumbai Pesisir, Kota Pekanbaru, Provinsi Riau. SMPN 06 Pekanbaru terdiri dari 1132 siswa dengan 506 siswa laki-laki dan 626 siswa perempuan dan didampingi 54 guru dan staff serta 3 orang penjaga sekolah, memiliki 15 bangunan merangkap 34 ruang kelas, 1 ruang guru, 1 perpustakaan, 1 mushalla, 2 laboraturium, dan 28 toilet.

Melalui sektor pendidikan, diharapkan implementasi PAH menjadi wadah untuk edukasi bagi siswa/i sekolah, guru, dan staf yang dapat pula dilanjutkan penerapannya pada lingkup keluarga masing-masing, serta menjadi kegiatan percontohan bagi sekolah lainnya dan masyarakat sekitar. Perlu penanganan yang serius secara bersama-sama terutama dengan penyediaan air bersih yang memadai menyesuaikan dengan kondisi kawasan agar penyediaan air bersih dapat terpenuhi disetiap kawasan (Putri et al., 2018).

\section{METODE}

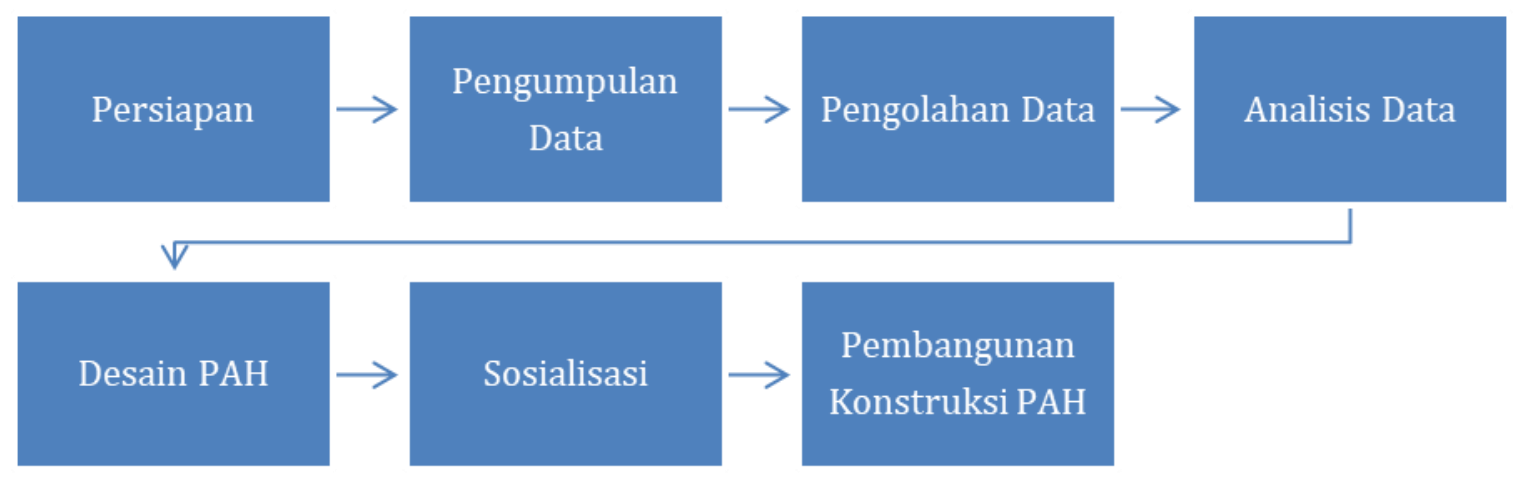

Gambar 1. Metode Pelaksanaan

Pelaksanaan kegiatan dimulai dengan melakukan Tahap persiapan, meliputi penentuan lokasi target lokasi, yang kemudian dilanjutkan dengan observasi lapangan, dan pembuatan surat kerjasama dengan mitra. Lokasi kegiatan terletak di Kota Pekanbaru, Kecamatan rumbai pesisir, tepatnya di SMPN 06 Pekanbaru. Kemudian dilanjutkan dengan kegiatan pengumpulan data. 
Pengumpulan data dilakukan dengan 3 cara, (1) Observasi secara langkung ke lokasi mitra dengan menerapkan protokol kesehatan; (2) wawancara secara daring dan luring dengan pihak mitra; (3) pengisian kusioner melalui google form.

Data yang digunakan ialah dat primer dan data skunder, adapun data primer yang digunkan dalam kegiatan ini dapat dilihat di bawah ini,

1. Data luas atap bangunan sekolah

2. Data jumlah siswa, guru, dan staff

3. Data total penggunaan air bersih di SMPN 06 Pekanbaru

Sedangkan data sekunder yang digunakan ialah data curah hujan pada tahun 2018 dan 2019 yang didapatkan dari Badan Pusat Statistik Kota pekanbaru,

Tabel 1. Data curah hujan di Pekanbaru tahun 2018 dan 2019

\begin{tabular}{|c|c|c|c|}
\hline \multirow[b]{2}{*}{ Bulan } & \multicolumn{2}{|c|}{ Jumlah Curah Hujan (mm3) } & \multirow{2}{*}{$\begin{array}{c}\text { Rata- } \\
\text { Rata } \\
(\mathrm{mm} 3)\end{array}$} \\
\hline & 2018 & 2019 & \\
\hline Maret & 68 & 163 & 115,5 \\
\hline Februari & 142 & 105 & 123,5 \\
\hline Maret & 309 & 96 & 202,5 \\
\hline April & 161 & 282 & 221,5 \\
\hline Mei & 249 & 163 & 206 \\
\hline Juni & 260 & 323 & 291,5 \\
\hline Juli & 125 & 74 & 99,5 \\
\hline Agustus & 108 & 43 & 75,5 \\
\hline September & 113 & 55 & 84 \\
\hline Oktober & 298 & 208 & 253 \\
\hline November & 333 & 316 & 324,5 \\
\hline Desember & 522 & 178 & 350 \\
\hline
\end{tabular}

Sumber: Badan Pusat Statistik Kota pekanbaru

Tabel 2. Data kebutuhan air per-hari bersih di SMPN 06 Pekanbaru

\begin{tabular}{|c|c|c|c|c|}
\hline Ket & Sektor & Volume & $\begin{array}{l}\text { Jmlh } \\
\text { Orang }\end{array}$ & Total Volume \\
\hline Sekolah & Sekolah & 10l/ Hari/ Org & 1186 & 11.860 L/ Hari \\
\hline Rumah Jaga & Rumah Tinggal & 120 L/Hari & 3 & 320 L/ Hari \\
\hline Masjid & Masjid & 5 L/ Hari/ Org & 1186 & 5930 L/ Hari \\
\hline
\end{tabular}

Sumber: Kriteria Perencanaan Ditjen Cipta Karya Dinas PU, 1996

\section{HASIL DAN PEMBAHASAN}

Sosialisasi dan Diskusi

Kegiatan Pengabdian kepada Masyarakat ini dilaksanakan dengan sistem hybrid yang dimulai pada tanggal 28 Juli hingga 27 Agustus 2021 di SMPN 06 Pekanbaru yang dihadiri oleh para siswa/i serta guru dan staff dari SMPN 06 Pekanbaru.

Materi penyeluhan dan diskusi yang disampaikan adalah tentang Pemanenan Air Hujan (PAH) Sebagai Upaya Implementasi SDG's (Sustainable Developent Goals) Sektor Air Bersih dan Sanitasi. Dimana siswa/i mengikuti kegiatan ini secara daring melalui media zoom, perserta 
yang hadir juga terlihat sangat antusias mengikuti acara penyuluhan. Pemberian sosialisasi materi dibagi menjadi 4 pertemuan dimana pertemuan ini terdiri:

1. Materi Konsep Pemanenan Air Hujan (PAH) tanggal 28 Juli 2021

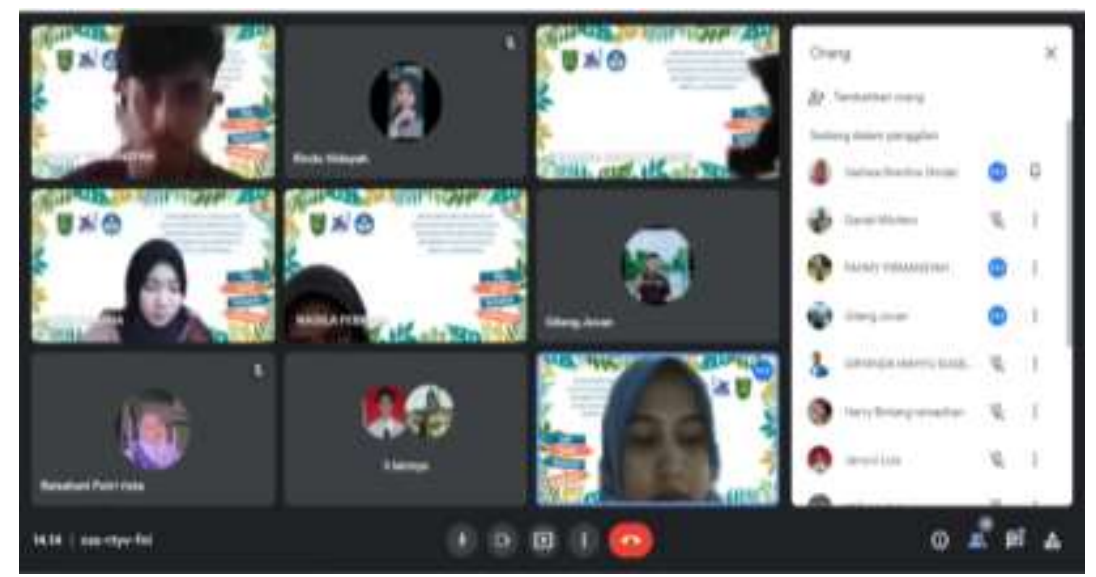

Gambar 2. Kegiatan Sosialisasi Materi Konsep Pemanenan Air Hujan (PAH)

2. Materi Konsep Air Bersih dan Sanitasi tanggal 31 Juli 2021

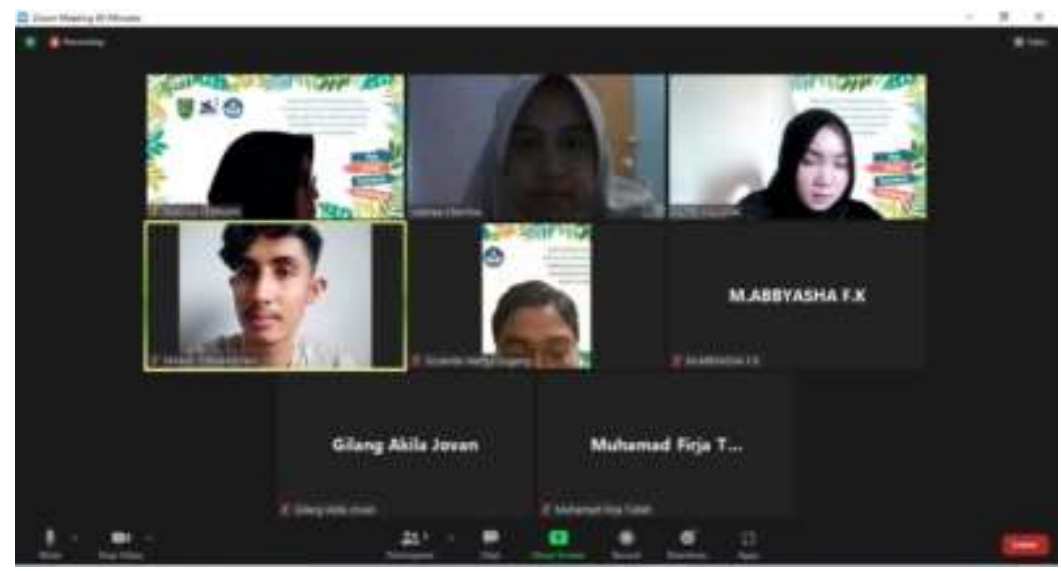

Gambar 3. Kegiatan Sosialisasi Materi Konsep Air Bersih dan Sanitasi

3. Materi Implementasi SDG’s tanggal 03 Agustus 2021

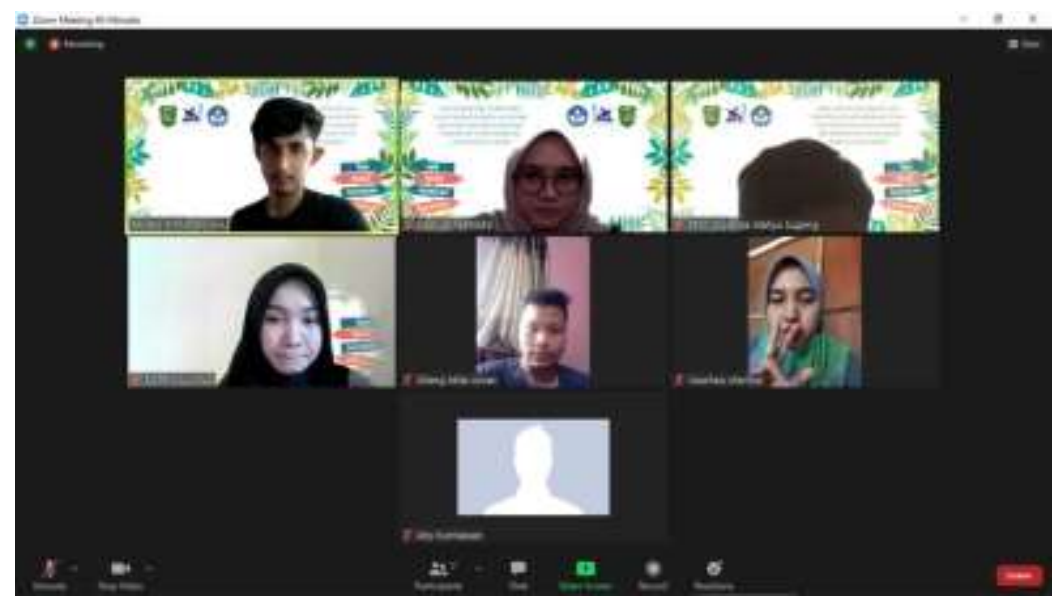

Gambar 4. Kegiatan Sosialisasi Materi Implementasi SDG'S 
4. Materi Desain Instalasi PAH Tanggal 05 Agustus 2021

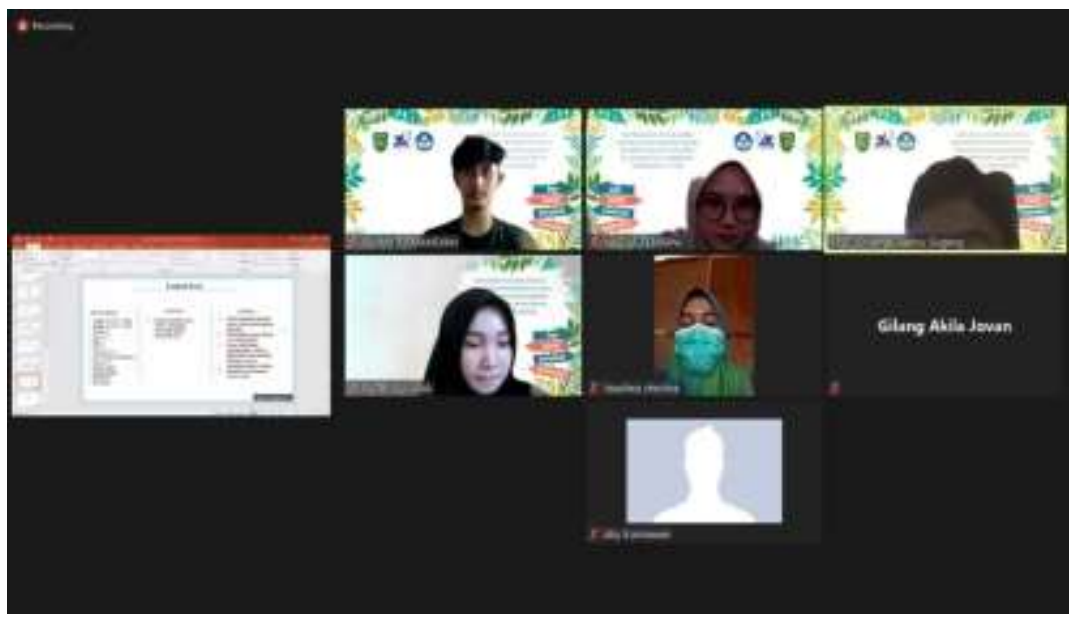

Gambar 5. Kegiatan Sosialisasi Materi Desain Instalasi PAH

\section{Demonstrasi}

Dalam kegiatan ini dilakukan secara luring bersama pihak mitra yaitu siswa/i berserta staff dan guru di SMPN 06 Pekanbaru. Kegiatan ini berlangsung selama 5 hari yang dapat disajikan pada Tabel 3.

Tabel 3. Tahap-Tahap Pembangunan PAH

\begin{tabular}{l} 
No Jenis Kegiatan \\
\hline Penyiapan alat dan bahan PAH \\
Tahap pemasangan talang air \\
32 \\
Persiapan kedudukan tangki air
\end{tabular}


$4 \quad$ Pemasangan sistem perpipaan

$5 \quad$ Pemasangan sistem pipa kedalam

bak filterasi serta saluran pembuangan

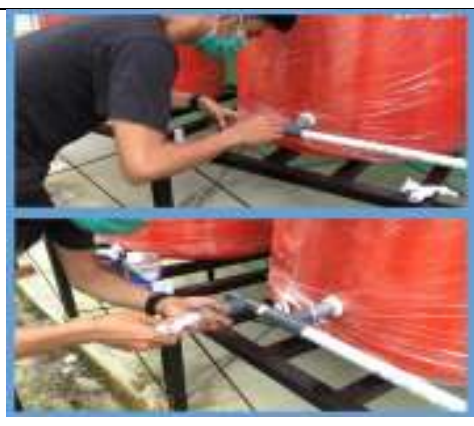
(2)

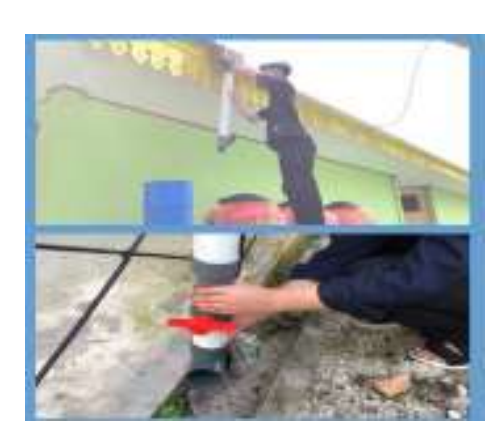

6 Proses pengisian komponen pada bak filterasi

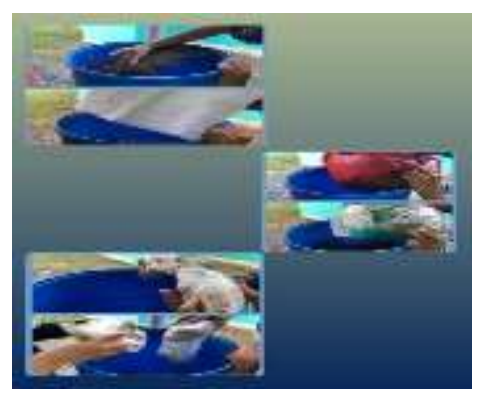

$7 \quad$ Evaluasi hasil progress $\mathrm{PAH}$ (mencuci tangan)

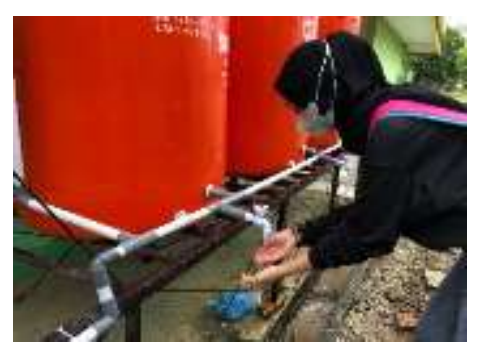

Bentuk sistem PAH yang telah di bangun

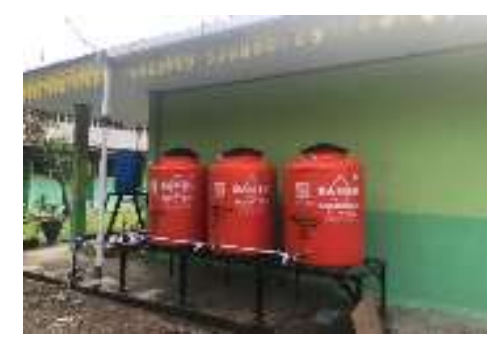

\section{Pre Test dan Post Test}

Dalam melakukan kegiatan sosisaliasi ini, dilakukan sistem pre test dan post test yang sebelumnya sudah diisi oleh para siswa/i, guru, dan staff. Kuesioner yang dibagikan berisi pertanyaan mulai dari pengertian $\mathrm{PAH}$, manfaat sampai dengan pengetahuan tentang SDG's mengenai sektor air bersih dan sanitasi. Berikut ini hasil dari sosialisasi serta implementasi PAH di SMPN 06 Pekanbaru disajikan pada Gambar 6. 


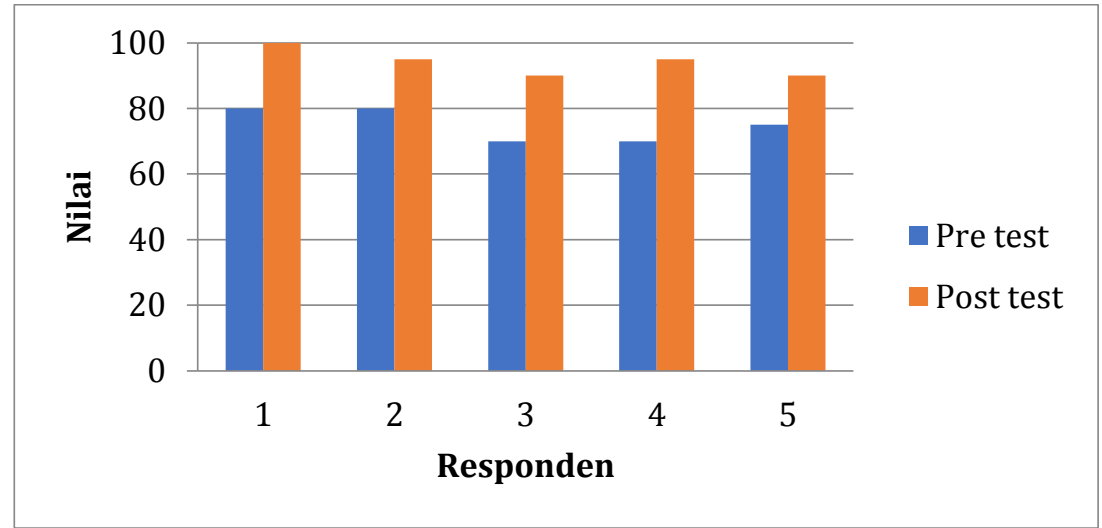

Gambar 6. Hasil Perbandingan Capaian Pengetahuan SDG's dan PAH

Hasil pengukuran yang disajikan pada Gambar 6 megambarkan bahwa mitra pada test kemampuan pre test umumnya mitra tidak mengetahui pengertian dari $\mathrm{PAH}$, manfaat serta manfaat dari SDG's. Setelah dilakukannya kegiatan sosialisasi berserta implementasi PAH di SMPN 06 Pekanbaru terjadi peningkatan pengetahuan tentang pengertian dari PAH, manfaat serta manfaat dari SDG's. Para siswa/i, guru dan staff termotivasi untuk ikut andil dalam menerapkan kegiatan ini di luar lingkup sekolah agar implementasi ini bukan hanya sekedar bermanfaat di sekolah tetapi dapat bermanfaat pada masyarakat luas serta tercapainya SDG's yang berkelanjutan.

\section{KESIMPULAN}

Implementasi PAH ini berpotensi membuka kerjasama yang sinergi dengan pemerintah (Pekerjaan Umum, Kementerian Lingkungan Hidup dan Kehutanan) untuk mendukung program SDG's sektor air bersih dan sanitasi. Selain itu, penyuluhan teknis kepada anggota osis diharapkan dapat memperluas sebaran IPTEK ke murid sekolah lainnya untuk kemudian berpotensi menjadi proyek percontohan bagi sekolah lainnya ynag dapat diterap kembangkan di masyarakat luas.

\section{UCAPAN TERIMA KASIH}

Penulis mengucapkan terima kasih kepada pihak mitra SMPN 06 Pekanbaru yang telah memberikan kesempatan untuk melakukan kegiatan pengabdian ini.

\section{DAFTAR PUSTAKA}

Alisjahbana, A. S. (2017). Menyongsong SDGs: kesiapan daerah-daerah di Indonesia. Unpad Press.

Putri, L. D. (2018). Potensi Pengembangan Utilitas Wilayah Kumuh Di Kelurahan Muara Fajar Kota Pekanbaru. Jurnal Teknik Sipil Unaya, 4(1), 11-20.

Putri, L. D., \& Harsini, S. R. (2018). Potential of Regulation of Slum Area in The Village Meranti Pandak Pekanbaru City. International Journal of Engineering \& Technology, 7(2), 466-469.

Quaresvita, C. 2016. Perencanaan Sistem Pemanenan Air Hujan Sebagai Alternatif Penyediaan Air Bersih (Studi Kasus Asrama Its). Skripsi. Fakultas Teknik Sipil Institut Teknologi Sepuluh Nopember, Surabaya.

Rofil, R., \& Maryono, M. (2017). Potensi dan Multifungsi Rainwater Harvesting (Pemanenan Air Hujan) di Sekolah bagi Infrastruktur Perkotaan. In Proceeding Biology Education Conference: Biology, Science, Enviromental, and Learning (Vol. 14, No. 1, pp. 247-251).

Yermadona, H., Femi Earnestly, Suryani, \& Firdaus. (2019). Penjernihan Air di RT 001/RW 013 Kelurahan Pasie Nan Tigo .Dinamisia : Jurnal Pengabdian Kepada Masyarakat,3(Juni). Retrieved from https://journal.unilak.ac.id/index.php/dinamisia/article/view/2872 